\title{
Do we need a cosmetic effect for radical nephrectomy? Laparoendoscopic single-site surgery would help to answer this question
}

\author{
Piotr Chłosta ${ }^{1,2}$, Tomasz Drewa ${ }^{3,4}$, Mateusz Obarzanowski ${ }^{1}$, Artur Antoniewicz' ${ }^{2}$ Andrzej Borówka ${ }^{2}$ \\ 1Department of Urology, Institute of Oncology, Kielce, Poland \\ 2Department of Urology, Centre of Postgraduate Urology Education, Postgraduate University, Warsaw, Poland \\ 3Department of Tissue Engineering, Collegium Medicum, Nicolaus Copernicus University, Bydgoszcz, Poland \\ 4Department of Urology, Institute of Oncology, Bydgoszcz, Poland
}

Videosurgery and other miniinvasive techniques 2011; 6 (1): 1-4 DOI: 10.5114/wiitm.2011.20985

\begin{abstract}
Introduction: The development of endovision techniques and equipment miniaturization in urology make it possible to perform laparoendoscopic single-site (LESS) nephrectomy. Radical nephrectomy due to renal cancer performed with LESS is not a standard procedure in urology.

Aim: To present our preliminary results and operative technique of LESS radical nephrectomy.

Material and methods: The study was carried out after team experience based on LESS radical nephrectomy performed from October 2009 to June 2010 in 11 cases. A single port with 3 working channels (Triport Access System, OLYMPUS ${ }^{\circledR}$ ) and a $5 \mathrm{~mm}$ laparoscope $30^{\circ}$ were used. The approach was created by minilaparotomy technique on the lateral margin of the rectus muscle, $4 \mathrm{~cm}$ above the umbilicus. The procedure was performed using standard laparoscopic instruments, bent or articulating graspers, and scissors. During the surgery metal and plastic clips were used, and a mechanical vascular stapler in two cases. In every case bipolar coagulation was used. The postoperative specimen was removed via single-port minilaparotomy. After surgery, one suction drain $14 \mathrm{~F}$ was left.

Results: In all patients the procedure was performed without conversion to standard, open technique. In two cases accessory port (10 and $12 \mathrm{~mm}$ ) placement was necessary, for organ retraction or insertion of a vascular stapler. Mean surgery time was $128 \mathrm{~min}$ (120-160 min). Mean blood loss was $155 \mathrm{ml}$ (100-250 ml). There were no complications during surgery or the postoperative period. Mean hospitalization stay was 4 days (3-5 days). Clinical stage of renal cell cancer (RCC) was pT1a in 1, pT1b in 9, and pT3a in 1 patient. The results of histopathological examination show typical RCC in 10 cases, and papillary RCC in 1.

Conclusions: LESS nephrectomy is effective but technically difficult. LESS nephrectomy is a considerably less invasive procedure than standard laparoscopic nephrectomy, unless accessory port placement is necessary. LESS offers a very good cosmetic effect, which can be an attribute of the single-site approach. LESS radical nephrectomy makes it possible to perform efficient and safe kidney excision and seems to be a valuable alternative to classic surgery in properly selected cases.
\end{abstract}

Key words: laparoendoscopic single-site surgery, laparoscopy, radical nephrectomy. 


\section{Introduction}

Laparoendoscopy using one working port is a rapidly developing branch of minimal invasive techniques in surgery, but experience with laparoendoscopic single-site (LESS) surgery is still small [1-4]. There are no indications for this kind of surgery as yet. In total, 315 LESS procedures have been performed due to urological indications. There were 163 LESS procedures relating to renal surgery, including renal cyst decortication, nephroureterectomy, nephron sparing surgery, excision of benign tumour, and live donor nephrectomy. We have noted 86 LESS procedures performed due to oncological disease of the kidney, renal cancer or ureter cancer (nephrectomy, nephroureterectomy, or nephron sparing surgery). In 37 surgeries LESS was used as a method to perform radical nephrectomy in the case of renal cell carcinoma [5-17].

Radical nephrectomy due to renal cancer performed with LESS is not a standard procedure in urology. The development of endovision techniques and equipment miniaturization in urology make it possible to perform LESS nephrectomy [13]. The LESS approach is popular for live donor nephrectomy, so we think that LESS can be successfully used to excise a cancer-bearing kidney. The aim of the study was to present our preliminary results of radical nephrectomies performed with the LESS approach.

\section{Material and methods}

Laparoendoscopic single-site nephrectomies were performed from October 2009 to June 2010 in 11 cases: 3 right kidney tumours and 8 on the left side. All tumours were classified as cT1 tumours characterized by borderline diameter between cT1a and cT1b stage with evident intrarenal growth. We assessed these kidneys as unfit for partial nephrectomy. The singlesite approach with 3 working channels (Triport Access System, OLYMPUS ${ }^{\circledR}$ ) and $5 \mathrm{~mm}$ laparoscope $30^{\circ}$ was used. The approach was created by minilaparotomy technique on the lateral margin of the rectus muscle, $4 \mathrm{~cm}$ above the umbilicus. The procedure was performed using standard laparoscopic instruments, bent or articulating graspers, and scissors. During the surgery metal and plastic clips were used, and a mechanical vascular stapler was employed in 2 cases. In every case bipolar coagulation was used. The postoperative specimen was removed via single-site minilaparotomy. After surgery, one suction drain $14 \mathrm{~F}$ was left. Only descriptive statistics were performed. Results are presented as means with ranges.

\section{Results}

In all patients the procedure was performed without conversion to standard, open technique. LESS equipment allowed the procedure to progress similar to classical laparoscopy and was equivalent to oncological requirements, i.e. artery dissection and clipping in the first step and kidney removal with Gerota's fascia. The renal vein was dissected and clipped in the next stage after cutting the arterial vessels. The ureter was left intact until the end of the procedure due to it helping to track and move the kidney during the dissection process. In 2 cases accessory port (10 and $12 \mathrm{~mm}$ ) placement was necessary, for organ retraction or insertion of a vascular stapler. Mean surgery time was $128 \mathrm{~min}$ (120-160 min). Mean blood loss was $155 \mathrm{ml}(100-250 \mathrm{ml})$. There were no complications during surgery or the postoperative period. Mean hospitalization stay was 4 days (3-5 days).

Histology revealed 10 clear cell renal cell carcinomas (cRCC, G-2 according Furman) and 1 papillary renal cell carcinoma ( $p R C C, G-2)$. One tumour was staged as pT1a with diameter of $4.0 \mathrm{~cm}$. Nine tumours were staged as pT1b; diameter range was 4.5 to $6.5 \mathrm{~cm}$. One tumour was pT3a due to renal vein invasion. In this case an infiltration was found in the greater part of the parenchyma with the remaining atrophic part of the kidney. Tumour diameter was $7.5 \mathrm{~cm}$ in this case.

\section{Discussion}

Laparoendoscopic single-site surgery represents the latest innovation in laparoscopic surgery for oncological diseases. Data referring to LESS technique are sparse but growing. Over 300 LESS procedures are recorded in medical databases. Thirtyseven radical nephrectomies have been performed using this approach [5-19]. We have presented 11 radical nephrectomies, so we think that our cases can serve as a substantial input to data referring to this issue. Park et al. presented 19 LESS radical nephrectomies due to localized RCC. They recorded mean operating time of $191 \mathrm{~min}$. Estimated blood loss was $143 \mathrm{ml}$. Postoperative hospital stay after LESS radical nephrectomy was 2.7 (2-4) days, compared with 
3.9 (3-7) days in the conventional laparoscopy group $(P<0.001)$. They also recorded lower postoperative pain after LESS when compared to conventional laparoscopy [5]. LESS was also proposed for nephroureterectomy with bladder cuff excision, but the intervention time increased to $385 \mathrm{~min}$ and $285 \mathrm{~min}$ for 2 cases presented by the same group [7]. Blood loss in the presented 2 cases was $100 \mathrm{ml}$ and $350 \mathrm{ml}$. Han and colleagues presented 14 patients who underwent simple nephrectomies using the LESS approach due to benign non-functioning kidneys [8]. The mean operative time was $151 \mathrm{~min}$, blood loss $108 \mathrm{ml}$, and postoperative hospital stay 3.1 (2-6) days. They recorded no major complications [8]. Ponsky et al. presented 1 case of LESS radical nephrectomy performed completely through a Pfannenstiel incision and GelPort. The procedure was completed in $187 \mathrm{~min}$. Blood loss was estimated as small as $50 \mathrm{ml}$. The patient was discharged after 2 days [9].

The laparoendoscopic single-site and Pfannenstiel approach has been used in such a complicated and risky procedure as donor nephrectomy in 6 patients [10]. Mean surgery time was $142 \mathrm{~min}$ and blood loss $100 \mathrm{ml}$. Patients were discharged after 2 days. There were no perioperative complications in the LESS group, but the authors of this study stated that the advantages of LESS might only be cosmetic [10]. Ganpule et al. reported 13 patients undergoing laparoendoscopic single-site live donor nephrectomy with similar good results, but only the cosmetic effect was superior to standard laparoscopy [11].

LESS is a new technique and complications could occur. Desai et al. reported the first 100 urological LESS procedures. They reported conversion to standard multi-port laparoscopy in 3 cases, addition of a single $5-\mathrm{mm}$ port was necessary in 3 cases, and conversion to open surgery was necessary in 4 cases. One death occurred following simple prostatectomy in a patient who refused transfusion following haemorrhage. Intra- and postoperative complications occurred in 5 and 9 cases, respectively [12]. White and colleagues presented their first urological patients treated with LESS surgery. Six patients required conversion to standard laparoscopy in this study [13]. We also experienced the necessity for an additional port due to organ retraction or insertion of a vascular stapler in 2 cases.

It has to be emphasized that the LESS technique is expanding and can be found as an approach for retroperitoneal space and for paediatric surgery indi- cation [14, 15]. LESS urological surgery is feasible, offers improved cosmesis, and may offer decreased pain. LESS nephrectomy is a technically difficult and considerably less invasive procedure than standard laparoscopic nephrectomy, unless accessory port placement is necessary. Radical nephrectomy is an oncological procedure and usually long-term results are needed to confirm that it is equal to laparoscopic or open radical nephrectomy. The cosmetic effects in oncology can be regarded as a questionable advantage, but when looking at the development of classical laparoscopy it seems that the LESS technique will replace laparoscopy in the near future [19-21]. Whether LESS urological surgery is superior to standard laparoscopy is currently speculative, but improvement in instrumentation is likely to expand the role of LESS in uro-oncology [22].

Short-term clinical outcomes and oncological results indicate that radical nephrectomy can be performed using LESS. This is an effective but technically difficult procedure. Looking at the development of classical laparoscopy, we think that the LESS technique will probably replace classical multi-port laparoscopy. LESS nephrectomy is a considerably less invasive procedure than standard laparoscopic nephrectomy, unless accessory port placement is necessary. LESS surgery is another great step towards "cosmetic surgery" in oncology. The cosmetic effect can be an attribute of the single-site approach. Observations of larger groups of treated patients will verify this method in the future. LESS radical nephrectomy makes it possible to perform efficient and safe kidney excision and seems to be a valuable alternative to classic surgery in properly selected cases.

\section{References}

1. Michalik M, Frask A, Orłowski M. NOTES (Natural Orifice Transluminal Endoscopic Surgery) - operacje przez naturalne otwory ciała. Videosurgery and other miniinvasive techniques 2007; 2: 98-102.

2. Witzling M, Michalik M, Pawlak M. NOTES in patients treated in intensive care units - the new challenge. Videosurgery and other miniinvasive techniques 2009; 4: 154-7.

3. Michalik M, Orłowski M, Frask A, et al. LESS (laparo-endoscopic single-site surgery) right hemicolectomy. Videosurgery and other miniinvasive techniques 2009; 4: 164-7.

4. Michalik M, Frask A, Trybull A, et al. Methods of treatment for gallbladder diseases. Videosurgery and other miniinvasive techniques 2009; 4: 121-5.

5. Park YH, Park JH, Jeong CW, et al. Comparison of laparoendoscopic single-site radical nephrectomy with conventional laparo- 
scopic radical nephrectomy for localized renal-cell carcinoma. J Endourol 2010; 24: 997-1003.

6. Jeon HG, Jeong W, Oh CK, et al. Initial experience with 50 laparoendoscopic single site surgeries using a homemade, single port device at a single center. J Urol 2010; 183: 1866-71.

7. Park YH, Park SY, Kim HH. Laparoendoscopic single-site nephroureterectomy with bladder cuff excision for upper urinary tract transitional-cell carcinoma: technical details based on oncologic principles. J Endourol 2010; 24: 563-6.

8. Han WK, Park YH, Jeon HG, et al. The feasibility of laparoendoscopic single-site nephrectomy: initial experience using homemade single-port device. Urology 2010; 76: 862-5.

9. Ponsky LE, Steinway ML, Lengu IJ, et al. A Pfannenstiel single-site nephrectomy and nephroureterectomy: a practical application of laparoendoscopic single-site surgery. Urology 2009; 74: 482-5.

10. Andonian S, Herati AS, Atalla MA, et al. Laparoendoscopic singlesite Pfannenstiel donor nephrectomy. Urology 2010; 75: 9-12.

11. Ganpule AP, Dhawan DR, Kurien A, et al. Laparoendoscopic single-site donor nephrectomy: a single-center experience. Urology 2009; 74: 1238-40.

12. Desai MM, Berger AK, Brandina R, et al. Laparoendoscopic singlesite surgery: initial hundred patients. Urology 2009; 74: 805-12.

13. White WM, Haber GP, Goel RK, et al. Single-port urological surgery: single-center experience with the first 100 cases. Urology 2009; 74: 801-4.

14. Ryu DS, Park WJ, Oh TH, et al. Retroperitoneal laparoendoscopic single-site surgery in urology: initial experience. J Endourol 2009; 23: 1857-62.

15. Bayazit Y, Aridogan IA, Abat D, et al. Pediatric transumbilical laparoendoscopic single-site nephroureterectomy: initial report. Urology 2009; 74: 1116-9.

16. Stolzenburg JU, Hellawell G, Kallidonis P, et al. Laparoendoscopic single-site surgery: early experience with tumor nephrectomy. J Endourol 2009; 23: 1287-92.

17. Łosin M, Czauderna P, Gołębiewski A, et al. Single incision laparoscopic adrenalectomy - initial experience. Videosurgery and other miniinvasive techniques 2010; 5: 104-6.

18. Stolzenburg JU, Kallidonis P, Hellawell G, et al. Technique of laparoscopic-endoscopic single-site surgery radical nephrectomy. Eur Urol 2009; 56: 644-50.

19. Berdjis N, Hakenberg OW, Leike S, et al. Comparison of transperitoneal versus retroperitoneal approach in laparoscopic radical nephrectomy for renal cell carcinoma: a single-center experience of 63 cases. Urol Int 2006; 77: 166-9.

20. Tsujihata M, Nonomura N, Momohara C, et al. Clinical experience with laparoscopic radical nephrectomy for renal cell carcinoma. Urol Int 2008; 81: 301-5.

21. Srivastava A, Gupta M, Singh P, et al. Laparoscopic radical nephrectomy: a journey from T1 to very large T2 tumors. Urol Int 2009; 82: 330-4.

22. Stolzenburg JU, Kallidonis P, Oh MA, et al. Comparative assessment of laparoscopic single-site surgery instruments to conventional laparoscopic in laboratory setting. J Endourol 2010; 24 : 239-45. 